\title{
RELACIONAMENTO COM CLIENTES DO SETOR FARMACÊUTICO EM VITÓRIA-ES: UMA ANÁLISE DOS IMPACTOS DO NÍVEL DE SERVIÇO ESPERADO E OFERTADO NA FIDELIZAÇÃO DOS CLIENTES
}

\author{
Mikaelli Orlande Gabriel \\ miklgabi@hotmail.com \\ Universidade Federal do Espírito Santo - Vitória, ES / Brasil \\ Anderson Soncini Pelissari \\ asoncinipelissari@gmail.com \\ Universidade Federal do Espírito Santo - Vitória, ES / Brasil \\ Marcos Paulo Valadares de Oliveira \\ marcos.p.oliveira@ufes.br \\ Universidade Federal do Espírito Santo - Vitória, ES / Brasil
}

Recebido em 30/03/2012

Aprovado em 20/06/2013

Disponibilizado em 01/04/2014

Avaliado pelo sistema double blind review

Revista Eletrônica de Administração

Editor: Luís Felipe Nascimento

ISSN 1413-2311 (versão on-line)

Editada pela Escola de Administração da Universidade Federal do Rio Grande do Sul.

Periodicidade: Quadrimestral

Sistema requerido: Adobe Acrobat Reader.

\section{RESUMO}

O mercado varejista farmacêutico passou por inúmeras mudanças nos últimos anos, tornandose mais competitivo e caracterizado por ofertas de produtos e serviços cada vez mais parecidas entre os diversos concorrentes. Uma das alternativas para as empresas desenvolverem vantagem em diferenciação nesse mercado é por meio da exploração de uma oferta amplificada de serviços, com maior qualidade no desenvolvimento de relacionamentos mais perenes com seus clientes. Neste trabalho são analisadas as relações entre a fidelidade do cliente e o nível de serviço ofertado, bem como com o nível de serviço esperado pelos clientes. Foi realizada uma pesquisa com 196 clientes de farmácias/drogarias da cidade de Vitória-ES a fim de obter informações acerca da expectativa do nível de serviço e sua percepção quanto ao nível de serviço ofertado pelas farmácias, assim como indicadores de fidelização desses indivíduos. Das cinco dimensões da escala SERVQUAL, apenas para a dimensão Segurança, foi verificado uma correspondência entre o nível de serviço esperado pelos clientes e o ofertado pelas farmácias. Em todas as outras, o serviço ofertado foi avaliado como inferior ao serviço esperado pelos clientes. Os resultados apontam para o fato que os clientes esperam mais que recebem nos fatores Tangibilidade, Confiabilidade, Responsividade e Empatia, o que não ocorre com o fator Segurança. Para aumentar a satisfação de seus clientes, as farmácias da cidade de Vitória devem melhorar o nível do serviço ofertado em tais fatores que apresentaram dissonância.

Palavras-chave: Fidelização; Varejo farmacêutico; Nível de serviço; Marketing de relacionamento. 
Mikaelli Orlande Gabriel, Anderson Soncini Pelissari \& Marcos Paulo Valadares de Oliveira

\title{
CUSTOMER RELATIONSHIP AT PHARMACEUTICAL INDUSTRY OF VITÓRIA- ES: AN IMPACT EVALUATION OF SERVICE LEVEL BOTH OFFERED AND EXPECTED OVER CUSTOMER FIDELITY
}

\begin{abstract}
The pharmaceutical retail market was subject of several changes along the last years and become more competitive and characterized by product and service offers looking like even more the same amongst several competitors. One of the alternatives for companies to develop differentiation competitive advantage at this market is to exploit an amplified service offer, with more quality, developing more perennial relationships with its customers. In this work the relationships between customer fidelity with the service level offered will be analyzed, as well the relationships between customer fidelity and the service level expected by customers. The data collection was conducted with 196 pharmacy/drugstore customers in Vitória-ES city in order to gather information about the service level expectation as well the perception about the service level offered by pharmacies. Indicators of the respondents fidelity as pharmacy customers were also collected. Considering the five dimensions of the SERVQUAL scale, a match was verified between service offered and expected by pharmacies only at the Assurance dimension. At the remaining dimensions the offered service was evaluated as lower than expected by customers. The results indicate that customers used to expect more than they get when Tangibles, Reliability, Responsiveness and Empathy dimensions were evaluated. After all, in order to increase customer's satisfaction, pharmacies at the city of Vitória-ES should pay attention and improve the service level offered in such dimensions where the dissonances were identified in order to become more competitive.
\end{abstract}

Keywords: Fidelity; Pharmaceutical retail market; Service level; Relationship marketing.

\section{INTRODUÇÃO}

O mercado brasileiro vem passando por inúmeras mudanças nas últimas décadas. A globalização, os adventos da tecnologia, o desenvolvimento econômico do país e a consequente entrada de várias empresas nacionais e internacionais no mercado, aceleraram a concorrência em quase todos os setores (LOPES, 2009; SALIBY, 1997; SANTOS, 2008). Paralelamente, com o crescimento na quantidade e diversidade de serviços e produtos ofertados no mercado bem como a facilidade e rapidez de acesso dos clientes aos diversos produtos e empresas, fez com que estes se tornassem cada vez mais exigentes (SALIBY, 1997; PEPPERS; ROGERS, 2001).

O mercado varejista caracteriza-se por ser um ambiente agressivo e de rápidas mudanças. Nesse contexto, os hábitos de compras dos brasileiros vêm mudando de forma acentuada nos últimos anos, provocadas por fatores como o crescente número de mulheres no mercado de trabalho, pouco tempo disponível para fazer compras, envelhecimento da população brasileira, entre outros (PARENTE, 2009; KOTLER, 2007).

REAd | Porto Alegre - Edição 77 - N 1 - janeiro/abril 2014 - p. 64-89 
Relacionamento com clientes do setor farmacêutico em Vitória-ES: uma análise dos impactos do nível de serviço esperado e ofertado na fidelização dos clientes

Dentro do contexto apresentado, encontram-se as empresas de varejo farmacêutico que, no Brasil, observou considerável expansão devido a fatores como o aumento do PIB, que promoveu a ascensão das classes $\mathrm{C}$ e $\mathrm{D}$, dando a estas um maior poder de compra. $\mathrm{O}$ crescimento dos genéricos, o aumento da população idosa no país e a diversificação do mix de produtos também representam fatores relevantes nesse contexto (KANNITZ, 2010; SEBRAE, s.d.).

Em 2009, as vendas de medicamentos nesse setor somaram $\mathrm{R} \$ 30,2$ bilhões e o Brasil era apontado como o $8^{\circ}$ mercado de medicamentos do mundo (IMS HEALTH, 2009). Porém, as expectativas para esse mercado apontam para um grande crescimento, entre $8 \%$ e $11 \%$ até 2013. Segundo pesquisas do IBOPE (2005), é na região sudeste que se encontra a maior concentração de farmácias, $57,5 \%$.

O varejo farmacêutico sofreu grande impacto com essas mudanças, já que nesse setor as possibilidades de diferenciação em relação à concorrência são baixas. Os produtos ofertados pelas farmácias são quase sempre os mesmos e a quantidade de empresas concorrendo pela mesma fatia de mercado é grande (PEREIRA; BASTOS, 2009).

Nesse sentido, as empresas vêm realizando um conjunto de ações para fidelizar e reter seus clientes mais valiosos, impedindo que eles migrem para a concorrência. No setor de serviços, as empresas buscam a fidelização e retenção dos clientes através, principalmente, da prestação de serviços com excelência, gerando uma combinação de preço e qualidade que proporcione maior valor ao cliente (PEREIRA; BASTOS, 2009). Diante da situação apresentada, chegouse ao seguinte problema de pesquisa: De acordo com a perspectiva do cliente, qual a relação entre fidelização e o nível de serviço esperado e ofertado pelas empresas do varejo farmacêutico da cidade de Vitória - ES?

Assim, o objetivo geral deste trabalho é identificar a relação existente entre o nível de serviço esperado, o nível de serviço ofertado e a fidelização do cliente no varejo farmacêutico na cidade de Vitória, Espírito Santo. Diante do exposto, esse trabalho encontra relevância na medida em que traz para as empresas do varejo farmacêutico, uma fonte para maior conhecimento de seus clientes, suas expectativas e percepções do que lhe é ofertado, bem como, quanto às possibilidades de fidelização a partir da oferta de serviços adequados. Para a academia, traz contribuições à medida que testa empiricamente, a relação entre o GAP, entre o nível de serviço esperado e o ofertado e a fidelização dos clientes. Há que se considerar ainda, as grandes transformações que vem ocorrendo na economia, particularmente em mercados em que o nível de competição se torna cada vez mais competitivo ao longo do 
Mikaelli Orlande Gabriel, Anderson Soncini Pelissari \& Marcos Paulo Valadares de Oliveira

tempo, sobretudo, tecnologicamente. A superioridade da qualidade dos produtos e serviços passa a ser determinante para a sobrevivência das organizações.

\section{FUNDAMENTAÇÃO TEÓRICA}

\subsection{Marketing de Serviço}

Berry e Parasuraman (1992) defendem a idéia de que o marketing de serviços é especialmente diferente do marketing de produto. Isso porque no marketing de mercadorias embaladas, a ênfase está na marca do produto. O marketing de produto é feito no sentido de "empurrar" o produto para o consumidor, já no marketing de serviços a ênfase está na marca da empresa e o marketing tem como objetivo "puxar" o cliente através da publicidade. Esses mesmos autores destacam, ainda, a criação de relacionamentos e contatos personalizados como sendo um instrumento primordial no marketing de serviços. Para Zeithaml e Bitner (2003) o marketing de serviços é diferente do marketing de mercadorias porque requer estratégias e táticas diferentes. A finalidade do marketing de serviços é de desenvolver fundamentos, técnicas e abordagens de marketing, com objetivo de atingir o mesmo nível de efetividade que o marketing de produto (ZEITHAML; PARASURAMAN; BERRY, 1985).

Como a qualidade dos serviços tem relação íntima com as expectativas dos clientes em relação ao serviço prestado, é fundamental no marketing de serviço que se gerencie as expectativas dos clientes, o que pode ser feito através da compreensão da maneira como os consumidores avaliam a qualidade dos serviços, os preços e as promoções (RODRIGUES, 2001).

\subsection{Fatores relacionados com a construção do relacionamento}

O desenvolvimento do marketing de relacionamento trouxe a necessidade de entendimento dos diversos fatores a ele relacionados e que poderiam explicar determinados comportamentos dos clientes. Essas variáveis, que são responsáveis por guiar o processo de decisão dos consumidores e suas ações em relações à empresa, são denominadas construtos de ordem superior e referem-se a conceitos como a satisfação do consumidor, a qualidade percebida do serviço e o valor percebido (BREI; ROSSI, 2005).

Toledo, Ikeda e Oliveira (2004) apresentaram em seus estudos que a fidelização dos clientes é fundamental para organizações que atuem em mercados altamente concorridos. Para esses autores, assim como para Barnes (2002), “o fornecimento de uma oferta de valor para o cliente é uma forma de satisfazê-lo, o que aumenta a probabilidade de que ele continue 
Relacionamento com clientes do setor farmacêutico em Vitória-ES: uma análise dos impactos do nível de serviço esperado e ofertado na fidelização dos clientes

consumindo o mesmo produto/marca e mantenha-se fiel à empresa" (TOLEDO; IKEDA; OLIVEIRA, 2004, pág. 12).

Apresenta-se a seguir alguns dos fatores relacionados ao marketing de relacionamento e presentes na teoria apresentada nos parágrafos anteriores: Valor, Qualidade, Satisfação, Retenção e Fidelidade.

\subsubsection{Valor}

Lovelock e Wirtz (2006, p. 20) conceituam valor como sendo "quanto vale uma ação ou objetivo especifico em relação às necessidades de um individuo ou organização em determinado momento, menos os custos na obtenção desses benefícios". Para criar valor para o cliente, a empresa deve entender o que é valor no ponto de vista do cliente ao invés de pressupor que o sabem, possibilitando assim, que ela ofereça os tipos de serviços que os clientes necessitam, a um preço aceitável (BARNES, 2002; LOVELOCK; WIRTZ, 2006).

Frequentemente, os clientes se deparam com inúmeras ofertas de produtos e serviços para escolher. Nessa situação o fator decisivo na escolha é o valor percebido pelo cliente, ou seja, a avaliação que este faz da diferença entre todos os benefícios e todos os custos de uma oferta ao mercado em relação às ofertas dos concorrentes (PORTER, 2004).

Para Berry e Parasuraman (1992) a arte do marketing de relacionamento gira em torno do valor e este, por sua vez, reflete o beneficio total que os clientes recebem pelo total do custo em que incorrem. Esses mesmos autores ressaltam ainda, assim como Rust et al (2001), que o valor não é composto apenas por preço baixo, sendo a qualidade do serviço prestado, um fator importantíssimo na construção do valor.

\subsubsection{Qualidade}

A percepção da qualidade dos serviços é muito variável, distintos clientes terão diferentes entendimentos e sensibilidade à qualidade do serviço prestada pela empresa. Por isso, muitas vezes o que as empresas julgam ser qualidade não coincide com o que os clientes consideram como tal (VAVRA, 1993; ROCHA; CHRISTENSEN, 1999; BERRY; PARASURAMAN, 1992). Portanto, o entendimento do que é qualidade para seus clientes ajuda a empresa a adaptar seus produtos e serviços a essas necessidades (ROCHA; CHRISTENSEN, 1999; KAPLAN; NORTON, 1997).

Essa diferença origina-se, principalmente, do fato de que quando os clientes avaliam a qualidade de um serviço, fazem esse julgamento a partir de algum padrão interno já existente, 
Mikaelli Orlande Gabriel, Anderson Soncini Pelissari \& Marcos Paulo Valadares de Oliveira

que é na verdade a base para as expectativas do cliente (LOVELOCK; WRIGHT, 2001). Para Pelissari et al (2011, pág. 41) "prestar serviços com qualidade requer, hoje, atitudes que não irão garantir total satisfação e fidelidade dos clientes, contudo auxiliam à conquistar a confiança dos mesmos, permitindo que se gaste menos na reconquista do cliente".

De acordo com Lovelock e Wright (2001), após comprarem e consumirem os serviços, os clientes comparam a qualidade do que receberam com a qualidade que esperavam receber. Caso a qualidade percebida pelo cliente fique abaixo do nível de serviço adequado para ele, ocorre um GAP - ou lacuna na qualidade - entre o desempenho do fornecedor de serviço e as expectativas dos clientes.

Com o objetivo de buscar um melhor entendimento da qualidade dos serviços ofertados aos clientes pelo mercado, Parasuraman, Zeithaml e Berry (1985) desenvolveram um modelo composto por 5 gaps que podem ocorrer em diversas partes do desempenho do serviço. Os gaps na qualidade do serviço são:

Gap 1: é a discrepância entre o que os gerentes acreditam que os clientes esperam e as necessidades e expectativas reais dos clientes;

Gap 2: é a discrepância entre as percepções dos gerentes sobre a expectativa do cliente e os padrões de qualidade estabelecidos para a entrega do serviço;

Gap 3: é a diferença entre especificação de qualidade nos serviços e o serviço realmente ofertado;

Gap 4: é a discrepância entre aquilo que é comunicado e oferecido ao cliente (propaganda) e aquilo que a companhia realmente entrega;

Gap 5: é a diferença entre o que o cliente espera e o que efetivamente a empresa lhe entrega, reflete o resultado de todos os outros 4 gaps.

Berry e Parasuraman (1992) comentam que a qualidade é a base do marketing de serviço, pois produz credibilidade para a publicidade e a equipe de vendas, incita a propaganda boca-aboca positiva, melhora a percepção de valores do cliente e aumenta a fidelidade..

Berry e Parasuraman (1992) constataram que a percepção que o cliente tem da qualidade não é um conceito unidimensional. Para eles, ao avaliar a qualidade dos serviços, os clientes examinam cinco dimensões: confiabilidade, sensibilidade, segurança, empatia e elementos tangíveis.

A confiabilidade é o fator mais importante na percepção da qualidade. Essa dimensão referese à confiança nos serviços da empresa e na sua capacidade de cumprir o que promete de 
Relacionamento com clientes do setor farmacêutico em Vitória-ES: uma análise dos impactos do nível de serviço esperado e ofertado na fidelização dos clientes

modo confiável e com precisão (KOTLER; HAYES; BLOOM, 2002; BERRY; PARASURAMAN, 1992).

A sensibilidade diz respeito à presença, à prontidão e à disposição do prestador de serviços para ajudar o cliente. Na avaliação dessa dimensão, é levado em conta a responsividade e a rapidez do profissional em analisar as preocupações, as necessidades, as perguntas e as reclamações do cliente, bem como a flexibilidade do prestador de serviços para se adaptar às necessidades peculiares ou as condições mutáveis que o cliente enfrenta (KOTLER; HAYES; BLOOM, 2002; BERRY; PARASURAMAN, 1992).

Outra dimensão muito importante é a segurança, principalmente porque os serviços são variáveis, o que deixa os clientes sem ter certeza sobre a qualidade final do que esta sendo comprado. Trata-se de elementos como o conhecimento e a cortesia dos empregados, bem como sua habilidade em passar confiança para o cliente. Nesse quesito, é importante inspirar confiança nos clientes, quanto maior a confiabilidade no serviço, maior o grau de segurança. Essa confiança pode advir de experiências anteriores bem sucedidas com a empresa, ou ainda, através da imagem corporativa, das credenciais dos prestadores de serviços, ou mesmo da experiência acumulada no setor (KOTLER; HAYES; BLOOM, 2002; BERRY; PARASURAMAN, 1992).

A empatia refere-se à capacidade da empresa em fazer com que cada cliente se sinta especial e importante. Para manter o nível de empatia alto é necessário que a empresa busque conhecer as necessidades e anseios de cada cliente (KOTLER; HAYES; BLOOM, 2002; BERRY; PARASURAMAN, 1992).

A última dimensão refere-se aos elementos tangíveis, que vêm da necessidade dos clientes de buscar indicações físicas que evidenciem a qualidade dos serviços prestados pela empresa. Portanto, é importante que as empresas dêem a devida atenção para elementos como instalações físicas, equipamentos, pessoal e materiais de comunicação que veiculem a imagem pretendida (KOTLER; HAYES; BLOOM, 2002; BERRY; PARASURAMAN, 1992).

A partir dessas dimensões, Zeithaml, Berry e Parasuraman (1988) elaboraram um instrumento de análise da qualidade percebida pelo cliente, o qual denominaram Escala SERVQUAL. Nela os entrevistados preenchem uma série de questões que medem suas expectativas em relação aos serviços bem como suas percepções do desempenho real do serviço ofertado. Quando as notas de desempenho percebido são inferiores às expectativas, é um sinal de baixa qualidade, sendo que o contrário indica boa qualidade. Corrêa e Caon (2008) destacam que, 
Mikaelli Orlande Gabriel, Anderson Soncini Pelissari \& Marcos Paulo Valadares de Oliveira

quando feita de maneira adequada, a gestão da qualidade dos serviços produz um pacote de valor que gera satisfação e torna os clientes fidelizados.

\subsubsection{Satisfação}

A satisfação do cliente é um conceito subjetivo e relativo, dependendo de como o cliente percebe o desempenho do produto em comparação com suas expectativas, seja em relação à situação da compra ou ao desempenho e consumo do produto/serviço (BARNES, 2002; KOTLER, 2007; VAVRA, 1993). Para Anderson, Fornell e Lehmann (1992) a satisfação é um constructo que depende da função valor, sendo definida como o quociente entre a qualidade percebida e o preço, ou pela relação entre os benefícios recebidos pelo cliente comparativamente aos custos ou sacrifícios incorridos para sua obtenção. "Para uma empresa ser competitiva precisa focar na qualidade dos seus serviços e produtos para alcançar a satisfação dos seus clientes" (LINS; NUNES; LIMA, 2009, pág. 10).

Boone e Kurtz (2009) afirmam que a satisfação do consumidor pode ser medida pelas lacunas entre o que eles esperam e o que percebem que receberam. Essas lacunas podem, então, ser favoráveis ou desfavoráveis, cabendo aos profissionais de marketing da empresa conhecer as necessidades dos clientes atuais e potenciais para que a empresa possa evitar as lacunas desfavoráveis. De acordo com Lovelock e Wirtz (2006), grande parte dos estudos sobre a satisfação é baseada na premissa de que a confirmação ou não confirmação das expectativas pré-consumo é determinante essencial da satisfação.

Rossi e Braga (2004) e Porter (2004) lembram ainda da relação direta entre clientes satisfeitos e a fidelização, porém, muito embora a busca pela satisfação possa ser usada na busca pela fidelidade dos clientes, ela não é por si só garantia de lealdade. (LOVELOCK; WIRTZ, 2006). "A satisfação ou insatisfação do cliente repercutirá certamente em futuros processos de decisão de compra" (CRESCITELLI; GUIMARÃES; MILANI, 2006, pág. 10).

\subsubsection{Retenção e Fidelidade}

O cliente fiel representa para a empresa uma fonte consistente de receita durante muitos anos (LOVELOCK; WIRTZ, 2006). Nesse sentido, Salomon (2008) afirma que a lealdade dos clientes é o maior ativo de uma empresa. Desenvolver os níveis mais elevados de satisfação leva a uma maior retenção e lealdade de clientes, ajudando a assegurar a empresa ao longo do tempo (PELISSARI et al, 2011). 
Relacionamento com clientes do setor farmacêutico em Vitória-ES: uma análise dos impactos do nível de serviço esperado e ofertado na fidelização dos clientes

A fidelidade do cliente a uma marca ou empresa pode ser encarada como a disposição do mesmo em continuar a prestigiar uma empresa no longo prazo, comprando seus bens e serviços regularmente e, de preferência, com exclusividade (LOVELOCK; WIRTZ, 2006).

Berry e Parasuraman (1992) propõem uma estrutura para a conquista da lealdade através da superação das expectativas do cliente, na qual a administração eficiente das expectativas do cliente leva a superação das mesmas e posteriormente a conquista da lealdade do cliente (BERRY; PARASURAMAN, 1992).

Lovelock e Wirtz (2006) destacam, ainda, que a fidelidade não pode ser considerada como certa. Os clientes só se manterão fiéis enquanto julgarem que estão recebendo o melhor valor do mercado.

De acordo com Pereira e Bastos (2009), as estratégias de fidelização e as de Marketing de Relacionamento estão intimamente ligadas, isso porque um cliente fiel automaticamente terá um relacionamento com a "marca" a qual escolheu ser fiel.

\subsection{Marketing de relacionamento}

Gordon (1998, pág. 31) define o marketing de relacionamento como sendo "o processo continuo de identificação e criação de novos valores com clientes individuais e o compartilhamento de seus benefícios durante uma vida toda de parcerias". Para Mello e Vieira (2008, pág. 4) "relacionamento é um termo que sugere, de um modo geral, confiança e interação entre dois ou mais indivíduos".

Olbrzymek, Olbrzymek e Bretzke (2005) constataram em seus estudos, que o marketing de relacionamento deve desenvolver ferramentas e meios que permitam contato direto com o cliente, mas ressaltam ainda que esse processo não se trata de encher os clientes com malasdiretas, emails, panfletos e telefonemas. Trata-se de desenvolver um contato quase que íntimo com os clientes, ofertando tempo necessário para atendê-lo e antecipando-se às suas necessidades para que o cliente se sinta tão importante que não queira trocar de fornecedor.

De acordo com Yamashita e Gouvêa (2007), uma postura proativa por parte da empresa, antecipando ou estimulando as necessidades dos clientes, atuando na prevenção de problemas como o mau atendimento ou, ainda, buscando proporcionar um serviço que ofereça maior valor para o cliente, é uma estratégia muito benéfica para a organização.

A grande vantagem do marketing de relacionamento está na possibilidade de fidelizar clientes que possuem alto valor para empresa (PEPPERS; ROGERS, 1994). Nesse mesmo sentido, Corrêa e Caon (2008) comentam que clientes fiéis e retidos trazem para a empresa uma 
Mikaelli Orlande Gabriel, Anderson Soncini Pelissari \& Marcos Paulo Valadares de Oliveira

lucratividade crescente ao longo dos anos. Por outro lado, a aquisição de novos clientes pode ser muito dispendiosa. Estudos mostram que, via de regra, custa à empresa cinco vezes mais a aquisição de novos clientes do que a manutenção dos já existentes (PEPPERS; ROGERS, 1994; VAVRA, 1993; BARNES 2002). "O marketing de relacionamento trata-se de relacionamentos em longo prazo voltados para o contexto organizacional, que tanto pode ser entre duas empresas, ou entre empresas e consumidores" (MELLO; VIEIRA, 2008, pág. 4).

Em muitas empresas há um grande número de procedimentos custosos envolvidos na aquisição de novos clientes como, por exemplo, as propagandas, promoções e verificações de crédito. Em contrapartida, nenhum desses gastos se repete quando um cliente antigo compra novamente com a empresa. Nesse caso, se não houver uma política de fidelização, em geral, os clientes comprarão uma única vez com a empresa e esses custos não serão recuperados pela empresa, o que fará com que ela continue tendo mais gastos desse tipo (BARNES, 2002; BERRY; PARASURAMAN, 1992; CORRÊA; CAON, 2008).

Os relacionamentos têm particular relevância em se tratando de empresas prestadoras de serviço, uma vez que essas empresas dependem das pessoas para prestar seus serviços (BARNES, 2002). Nesse mesmo sentido, Mota e Freitas (2008) concluíram em seus estudos que as empresas de serviços devem perceber seus funcionários como o meio mais seguro para proporcionar relações mais fortes e duradouras com seus consumidores. Afirmam, ainda, que o sentimento positivo que os consumidores têm com os empregados são transferidos para a empresa.

\subsection{Varejo farmacêutico}

Números divulgados pelo Conselho Federal de Farmácias (CFF) e pelo Conselho Regional de Farmácias do Espírito Santo (CRFES) indicam que no Brasil, existem 79.010 estabelecimentos registrados como farmácia ou drogaria, dessas, 1.568 encontram-se no estado do Espírito Santo.

Conforme a Lei $\mathrm{n}^{\mathrm{o}} 5.991$ de 17 de dezembro de 1973, Drogaria é definida como "estabelecimento de dispensação e comércio de drogas, medicamentos, insumos farmacêuticos e correlatos em suas embalagens originais”. Já as Farmácias (sejam elas de manipulação ou homeopáticas) são definidas como:

"estabelecimentos de manipulação de fórmulas magistrais e oficinas, do comércio de drogas, medicamentos, insumos farmacêuticos e correlatos, compreendendo o de dispensação e o de atendimento privativo de unidade hospitalar ou de qualquer outra equivalente de assistência médica" (Lei nº 5.991/73, art. $4^{\circ}$, inciso X). 
Relacionamento com clientes do setor farmacêutico em Vitória-ES: uma análise dos impactos do nível de serviço esperado e ofertado na fidelização dos clientes

Apesar da diferença definida em Lei, o que se observa na pratica é que a maioria das empresas que se restringem ao comercio dos medicamentos utiliza a razão social "farmácia e drogaria" (SEBRAE, 2000). Frente a esta realidade, utilizou-se para efeito desse estudo todos os estabelecimentos com denominação "farmácia", "drogaria" ou ainda "farmácia e drogaria" denominando-os, para efeito de simplificação, apenas de "farmácia". Segundo dados do Conselho Regional de Farmácias do Espírito Santo (CRFES), existem, na cidade de Vitória, 35 farmácias e 129 drogarias. Levando em consideração que a Organização Mundial de Saúde (OMS) recomenda a proporção de uma farmácia para cada 10 mil habitantes e que a cidade de Vitória possui um total de 320.153 moradores (IBGE, 2010), pode-se afirmar que há uma grande concentração de farmácias nessa região, numa proporção de 1 farmácia para cada 1.952 habitantes. Como a concorrência no setor é cada vez mais acirrada, as empresas têm adotado diversas estratégias para superar os obstáculos encontrados. A partir daí, muitas são as tendências observadas nesse setor como forma de sobreviver à concorrência:

1) SERVIÇOS ADICIONAIS: as farmácias estão oferecendo serviços como pagamento de contas de água, luz e telefone. Apesar de o lucro proveniente desses serviços adicionais ser pequeno, eles ganham um diferencial em relação à concorrência e aumentam a circulação de pessoas no estabelecimento, aumentando também as vendas, já que cerca de $30 \%$ das pessoas que vão pagar suas contas acabam comprando ao menos um produto da loja (SAAB; RIBEIRO, 2001).

2) MIX DE PRODUTOS: A venda de produtos de bem estar, saúde e beleza representam uma forte tendência do setor, já que possuem uma margem de lucro consideravelmente maior a dos medicamentos em si. Esse artifício vem ganhado cada vez mais força devido à falta de tempo dos consumidores, o que faz com que as pessoas procurem as opções que lhes proporcionem mais rapidez e praticidade, fortalecendo a disposição em comprar o máximo de produtos em um mesmo local. Com o mix de produtos cada vez mais diversificado, também é bastante comum encontrar itens como livros, revistas, xampus, barras de cereais, balas e chocolates nas farmácias brasileiras (LUIZ; BRAGA, 2006; SAAB; RIBEIRO, 2001; HSM, 2009).

3) MARCA PRÓPRIA: muitas empresas estão investindo na criação de marcas próprias. Geralmente são produtos de higiene pessoal e cosméticos, ou ainda produtos básicos de farmácia e que representam um diferencial principalmente por apresentarem preços baixos (geralmente $30 \%$ abaixo das marcas tradicionais). Além disso, fortalecem o nome do estabelecimento e aumentam a fidelização do cliente já que, uma vez que o produto foi aceito 
Mikaelli Orlande Gabriel, Anderson Soncini Pelissari \& Marcos Paulo Valadares de Oliveira

pelo cliente, no momento de uma necessidade futura este tende a retornar à loja para adquirir novamente o produto (SAAB; RIBEIRO, 2001).

Outrora, o que predominava nesse setor era uma política de marketing de massa, porém, o que se busca atualmente, na intenção de fazer frente às novas condições do mercado, são políticas de marketing que priorizem o relacionamento, criando assim resultados, não à curto prazo, mas sim à médio e longo prazos (COMFAR, 2008). Nesse sentido, as farmácias estão adotando ações como: entregas em domicílios sem taxa extra ou pedido mínimo; serviço de atendimento ao cliente; drive-thru; banco 24 horas; call centers; convênio-empresa; vendas através de sites na internet; cartões de fidelidade e descontos progressivos (SAAB; RIBEIRO, 2001).

Pode-se fazer ainda, algumas considerações a respeito do relacionamento entre farmácias e seus clientes, a partir de alguns estudos já realizados no Brasil:

- De modo geral, 68\% dos clientes são fieis às marcas dos remédios, não aceitando trocá-los. Verificou-se então que a prática da chamada “empurroterapia" nesse mercado não é bem vista pelos clientes (CORRÊA, 2004; GOUVEA; BIAZZI, 2007).

- A fidelidade dos clientes nesse mercado esta intimamente ligada à qualidade do atendimento e à confiança que o cliente tem no atendente. Detectou-se que, dos motivos que levam o consumidor a comprar em outra empresa, 70\% está ligada a fatores referentes ao atendimento (falta de contato e de atenção individual, atenção recebida de baixa qualidade, ou ainda atendimento rude e desatencioso) (CORRÊA, 2004).

- Dentre os benefícios oferecidos pelo "Cartão Fidelidade" os descontos são considerados os mais relevantes, superando a troca de pontos por brindes e prêmios (PEREIRA; BASTOS, 2009).

- Além do atendimento e preço baixo, a proximidade da farmácia em relação a casa ou trabalho e estacionamento com fácil acesso também apresentaram alto grau de importância na hora da escolha de um estabelecimento para realizar as compras (PEREIRA; BASTOS, 2009).

\section{METODOLOGIA}

A presente pesquisa tem como forma de abordagem a indução, definida por Lakatos e Marconi (2004, p. 53) como "um processo mental por intermédio do qual, partindo de dados 
Relacionamento com clientes do setor farmacêutico em Vitória-ES: uma análise dos impactos do nível de serviço esperado e ofertado na fidelização dos clientes

particulares, suficientemente constatados, infere-se uma verdade geral ou universal, não contida nas partes examinadas". Quanto a natureza quantitativa, a abordagem caracteriza-se pela utilização da quantificação na coleta e no tratamento de dados, tendo como intenção “garantir a precisão dos resultados, evitar distorções de análise e interpretação, possibilitando, conseqüentemente, uma margem de segurança quanto as inferências" (RICHARDSON, 1999, p.70), e ainda um enfoque descritivo que se caracteriza pela procura por "descobrir, com a maior precisão possível, a freqüência com que um fenômeno ocorre, sua relação e conexão com outros, sua natureza e características" (CERVO; BERVIAN; DA SILVA, 2007, p. 61).

Foi realizada uma pesquisa bibliográfica e documental e uma pesquisa de campo. Para tanto, inicialmente foram coletados dados secundários com o objetivo de levantar um arcabouço teórico que embasasse este trabalho. Nessa etapa, foram realizadas pesquisas bibliográficas em livros, artigos científicos e diretórios da internet, bem como coleta de dados nas associações e sindicatos das farmácias e também no SEBRAE do Espírito Santo. Na pesquisa de campo, utilizou-se o levantamento por amostragem.

Optou-se, nesta pesquisa, pelo uso do questionário e o tratamento dos dados foi realizado através das planilhas dinâmicas do software EXCEL e do software SPSS.

O universo desta pesquisa é formado por pessoas do gênero masculino e feminino, com idade superior a 20 (vinte) anos, que realizam compras em farmácias e/ou drogarias e residentes na Cidade de Vitória - Espírito Santo, Brasil.

Tabela 1 - População-alvo da pesquisa

\begin{tabular}{|c|c|c|c|c|}
\hline \multicolumn{5}{|c|}{ POPULAC̃O-ALVO DA PESQUISA } \\
\hline 20 a 29 anos & 30 a 39 anos & 40 a 49 anos & Acima de 50 anos & TOTAL \\
\hline 59.181 & 50.649 & 44.803 & 72.634 & 227.267 \\
\hline
\end{tabular}

Fonte: IBGE - Estimativas elaboradas no âmbito do Projeto UNFPA/IBGE (BRA/4/P31A)- População e Desenvolvimento. Coordenação de População e Indicadores Sociais - Adaptado pelos autores (2011).

Como o universo da pesquisa é amplo - 227.267 indivíduos, segundo estimativas do IBGE (2010) - tornou-se necessário fazer a pesquisa com uma amostra significativa dessa população-alvo. O cálculo do tamanho amostral foi realizado através da fórmula de Berni (2002), considerando um erro amostral tolerável de 7,14\%, fazendo-se assim necessário, a realização da pesquisa com 196 indivíduos pertencentes à população-alvo da pesquisa.

Utilizou-se o tipo de amostra não probabilística por quotas, pois os elementos da população foram selecionados respeitando-se quotas de região geográfica e faixa etária. Buscou-se com esse método, obter uma amostra que retratasse os diversos panoramas que podem ser 
Mikaelli Orlande Gabriel, Anderson Soncini Pelissari \& Marcos Paulo Valadares de Oliveira

encontrados nas diferentes regiões na cidade de Vitória, bem como uma representatividade proporcional de cada faixa etária integrante da população-alvo da pesquisa. Para tanto, a cidade de Vitória foi dividida em oito regiões, coincidentes com as regiões administrativas de Vitória, conforme delimitação utilizada pela prefeitura da cidade.

A quantidade de questionários aplicados em cada uma das oito regiões foi definida através do cálculo da porcentagem que a área de cada região representa da área total de Vitória, aplicando-se em seguida esse percentual encontrado sobre a quantidade total de questionários da pesquisa. Sendo assim, em cada uma das oito regiões, foi aplicada uma quantidade de questionários proporcional a porcentagem que a área de cada região representa da área total de Vitória (TABELA 2).

Tabela 2 - Distribuição dos questionários por área

\begin{tabular}{|c|c|c|c|c|c|c|c|c|c|}
\cline { 2 - 10 } \multicolumn{1}{c|}{} & Região I & Região II & Região III & Região IV & Região V & Região VI & Região VII & Região VIII & Vitória \\
\hline ÁREA (M²) & 2.201 .923 & 4.649 .790 & 4.376 .542 & 5.671 .517 & 5.315 .956 & 13.007 .200 & 3.600 .782 & 2.605 .116 & $\mathbf{4 1 . 4 2 8 . 8 2 6}$ \\
\hline $\begin{array}{c}\text { \%DA ÁREA DE } \\
\text { VITÓRIA }\end{array}$ & $5 \%$ & $11 \%$ & $11 \%$ & $14 \%$ & $13 \%$ & $31 \%$ & $9 \%$ & $6 \%$ & $\mathbf{1 0 0 \%}$ \\
\hline $\begin{array}{c}\text { QUESTIONARIOS POR } \\
\text { ÁREA }\end{array}$ & 10 & 22 & 22 & 27 & 25 & 61 & 17 & 12 & 196 \\
\hline
\end{tabular}

Fonte: Elaborado pelos autores (2011).

Após definir a quantidade de questionários a ser aplicado em cada região, calculou-se a quantidade que deveria ser reservada a cada faixa etária. Como a quantidade de moradores de Vitória na faixa de 20 a 29 anos é de 59.181 (IBGE, 2010) e sendo esse valor correspondente a $26 \%$ da população total da pesquisa, determinou-se que em cada uma das oito regiões deveriam ser aplicados $26 \%$ de cada quota regional de questionários a indivíduos com idade entre 20 e 29 anos. O mesmo procedimento foi realizado nas demais faixas etárias como demonstrado na Tabela 3. Sendo assim, a quantidade total de questionários aplicados em cada região foi dividida na mesma proporção de faixa etária da população-alvo da pesquisa.

Tabela 3 - Distribuição dos questionários por área e faixa etária.

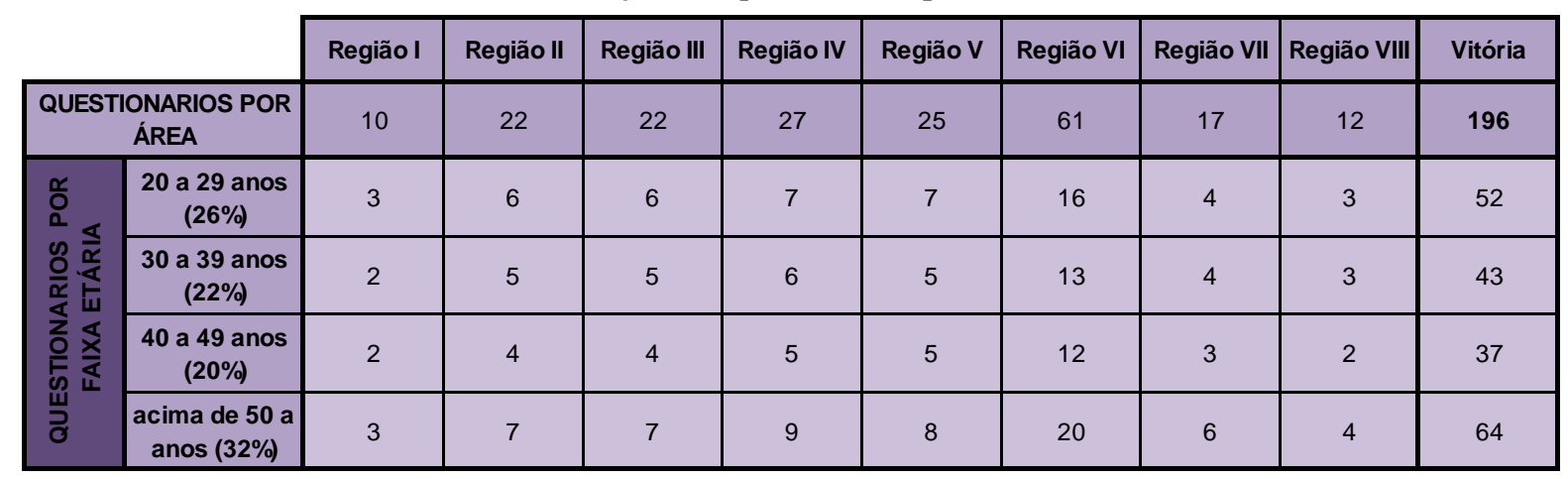

Fonte: Elaborado pelos autores (2011).

REAd | Porto Alegre - Edição 77 - N 1 - janeiro/abril 2014 - p. 64-89 
Relacionamento com clientes do setor farmacêutico em Vitória-ES: uma análise dos impactos do nível de serviço esperado e ofertado na fidelização dos clientes

Foi realizado um pré-teste do questionário, para verificar a clareza e precisão dos itens e questões, quantidade de perguntas e até a ordem de aparecimento das mesmas. O pré-teste foi aplicado a um grupo de 12 pessoas e a partir de suas dúvidas, foram feitas algumas alterações no questionário inicial.

A aplicação dos questionários foi realizada no período de 5 de janeiro a 2 de março de 2011, sendo realizado por um dos autores e mais um pesquisador devidamente instruído quanto as cotas de região e idade a serem respeitadas.

\section{ANÁLISE E INTERPRETAÇÃO DOS DADOS}

\subsection{Descrição do perfil da amostra}

Com relação ao gênero, $62 \%$ da amostra é do sexo feminino e $38 \%$ é do masculino. No que diz respeito ao estado civil a predominância é de Casados, 46\%, e Solteiros, 40\%, Viúvos e Separados correspondem a $7 \%$ da amostra cada. Os respondentes com apenas o Ensino Fundamental, corresponde a 15\% da amostra, enquanto que os com Ensino Médio e Superior somam 38\% cada, os outros $9 \%$ são Pós-Graduados. Por fim tem-se que $15 \%$ dos entrevistados pertencem à classe $\mathrm{A}, 14 \%$ à classe $\mathrm{B}, 46 \%$ à classe $\mathrm{C}, 16 \%$ à classe $\mathrm{D}$, e $9 \%$ à classe E, segundo classificação do IBGE. Quando perguntados se costumam comprar sempre em uma mesma farmácia, $65 \%$ responderam que Sim e $35 \%$ que Não.

\subsection{Teste de hipóteses}

Foram levantadas seis hipóteses neste trabalho e, para testá-las, foi realizado o teste de correlação para as variáveis em questão. Os resultados foram representados na tabela 4. De acordo com a definição de Lovelock e Wirtz (2006), já apresentado anteriormente, a fidelidade do cliente é a disposição do mesmo em continuar a prestigiar uma empresa no longo prazo, comprando seus bens e serviços regularmente e de preferência com exclusividade. Assim, o termo fidelidade denota uma condição relativamente duradoura e exige que a ação de comprar ocorra no mínimo duas vezes. Esses dois fatores - tempo de clientela e freqüência de compra - foram utilizados como indicadores de fidelidade nas hipóteses de 1 a 4.

Tabela 4 - Resultados do teste de Correlação para Hipóteses.

\begin{tabular}{|c|c|c|c|c|}
\hline Hipótese & Relação Estudada & $\begin{array}{c}\text { Coeficiente de } \\
\text { Correlação }\end{array}$ & Significância & Resultado \\
\hline Hipótese 1 & Freqüência de compra na mesma & 0,062 & 0,491 & Rejeitada \\
\hline
\end{tabular}

REAd | Porto Alegre - Edição 77 - N 1 - janeiro/abril 2014 - p. 64-89 
Mikaelli Orlande Gabriel, Anderson Soncini Pelissari \& Marcos Paulo Valadares de Oliveira

\begin{tabular}{|c|c|c|c|c|}
\hline & farmácia & & & \\
\hline & Nível de Serviço Ofertado & & & \\
\hline \multirow{2}{*}{ Hipótese 2} & $\begin{array}{l}\text { Freqüiência de compra na mesma } \\
\text { farmácia }\end{array}$ & \multirow{2}{*}{$-0,078$} & \multirow{2}{*}{0,390} & \multirow{2}{*}{ Rejeitada } \\
\hline & Diferença entre Médias dos níveis & & & \\
\hline \multirow{2}{*}{ Hipótese 3} & $\begin{array}{l}\text { Tempo em que é cliente desta } \\
\text { farmácia }\end{array}$ & \multirow{2}{*}{$-0,078$} & \multirow{2}{*}{0,388} & \multirow{2}{*}{ Rejeitada } \\
\hline & Nível de Serviço Ofertado & & & \\
\hline \multirow{2}{*}{ Hipótese 4} & $\begin{array}{l}\text { Tempo em que é cliente desta } \\
\text { farmácia }\end{array}$ & \multirow{2}{*}{0,051} & \multirow{2}{*}{0,576} & \multirow{2}{*}{ Rejeitada } \\
\hline & Diferença entre Médias dos níveis & & & \\
\hline \multirow{2}{*}{ Hipótese 5} & Nível de Satisfação & \multirow{2}{*}{$0,262^{* *}$} & \multirow{2}{*}{0,003} & \multirow{2}{*}{ Aceita } \\
\hline & Nível de Serviço Ofertado & & & \\
\hline \multirow[b]{2}{*}{ Hipótese 6} & Nível de Satisfação & \multirow[b]{2}{*}{$-0,177 *$} & \multirow[b]{2}{*}{0,049} & \multirow[b]{2}{*}{ Aceita } \\
\hline & Diferença entre Médias dos níveis & & & \\
\hline
\end{tabular}

*. Correlação é significativa no nível de 0,05.

**. Correlação é significativa no nível de 0,01 .

Fonte: Elaborado pelos autores (2011).

Hipótese 1: Quanto maior for a avaliação dos clientes para o nível de serviço ofertado, maior será a freqüiência de compras no estabelecimento.

A primeira hipótese levantada nesse trabalho é a de que o nível de serviço ofertado pelas farmácias da região de Vitória influencia diretamente na frequiência com que os clientes fazem suas compras nesse estabelecimento. Através dos resultados do teste de correlação não foi possível afirmar que haja uma relação entre o nível de serviço ofertado e a freqüência de compra no estabelecimento.

Hipótese 2: Quanto menor a diferença entre o nível de serviço esperado e o nível de serviço ofertado, maior a freqüência de compras no estabelecimento.

A segunda hipótese é a de quanto mais próximo estiver o nível de serviço ofertado pelas empresas do nível de serviço esperado pelos clientes, maior será a freqüência de compras destes clientes neste estabelecimento. O teste de correlação confirmou a relação inversa sugerida na hipótese, porém o resultado não foi significativo, o que não permite que a hipótese seja aceita.

Para as hipóteses 1 e 2 considerou-se a freqüência de compra como um indicador de fidelidade, assim buscou-se verificar a influência do nível de serviço na fidelidade segundo esse indicador. Como as duas hipóteses foram refutadas verificou-se que altos níveis de serviços não são fatores que influenciam na freqüência de compra dos clientes nas farmácias. 
Relacionamento com clientes do setor farmacêutico em Vitória-ES: uma análise dos impactos do nível de serviço esperado e ofertado na fidelização dos clientes

Também não foi encontrada relação entre a lacuna de nível de serviço ofertado e esperado e a freqüência de compra.

Hipótese 3: Quanto maior for a avaliação dos clientes para o nível de serviço ofertado, mais duradouros são os relacionamentos entre empresa e cliente.

A terceira Hipótese é de que relacionamentos longos entre os clientes e as farmácias de Vitória se sustentam por altos níveis de serviços ofertados. Realizou-se o teste de Correlação para melhor avaliar essa questão, os resultados não possibilitaram que essa relação seja feita.

Hipótese 4: Quanto menor a diferença entre o nível de serviço esperado e o nível de serviço ofertado, mais duradouros são os relacionamentos entre clientes.

O índice da correlação entre o tempo de clientela e a lacuna entre o nível de serviço esperado e o nível de serviço ofertado foi inferior a 0,3, considerado fraco. Além de fraca, essa correlação tem um nível de significância de 0,576. Por tanto, a Hipótese 4 também deve ser rejeitada. Assim, com os resultado das hipóteses 3 e 4, verificou-se que nem o nível de serviço nem a lacuna entre o nível de serviço esperado e ofertado influenciam no tempo de relacionamento do cliente com o estabelecimento.

Hipótese 5: Quanto maior for a avaliação dos clientes para o nível de serviço ofertado, maior também o nível de satisfação dos clientes.

Outra hipótese levantada é a de que altos níveis de serviços ofertados geram altos níveis de satisfação. Para testar essa hipótese foi realizado o teste de correlação e os resultados demonstraram que há uma correlação entre o nível de serviço ofertado e o nível de satisfação dos clientes das farmácias de Vitoria, que apesar de fraca é muito significativa. Então, a Hipótese 5 deve ser aceita. Esse teste de hipótese confirmou que os níveis de serviços ofertados refletem diretamente na satisfação dos clientes, por tanto, altos níveis de serviços geram clientes satisfeitos.

Hipótese 6: Quanto menor a diferença entre o nível de serviço esperado e o nível de serviço ofertado, maior a satisfação dos clientes.

A última hipótese também foi aceita, uma vez que os resultados indicaram uma correlação inversa e fraca entre o nível de satisfação dos clientes e a lacuna entre o nível de serviço esperado e o nível de serviço ofertado. Apesar de fraca, essa correlação tem um nível de significância de 0,049 , o que permite que ela seja aceita.

Assim, o resultado da análise da hipótese 6 confirma o encontrado na literatura anteriormente exposta de que a satisfação do consumidor esta relacionada com a confirmação das expectativas deste sobre o serviço. Reforça ainda a recomendação feita por Boone e Kurtz

REAd | Porto Alegre - Edição 77 - N 1 - janeiro/abril 2014 - p. 64-89 
Mikaelli Orlande Gabriel, Anderson Soncini Pelissari \& Marcos Paulo Valadares de Oliveira

(2009), de que as empresas devem conhecer seus clientes e conseqüentemente suas expectativas, para evitar que a lacuna entre o serviço esperado e o serviço ofertado seja negativa e para evitar que seus clientes fiquem insatisfeitos.

\subsection{Avaliação do nível de serviço esperado e ofertado a partir da escala SERVQUAL}

$\mathrm{Na}$ segunda e terceira parte do questionário, buscou-se analisar a percepção do cliente quanto ao nível de serviço que se espera das farmácias e ao nível de serviço ofertado pelas farmácias. As questões foram elaboradas com base na Escala SERVQUAL, possibilitando a análise das dimensões: Tangibilidade, Confiabilidade, Responsividade, Segurança e Empatia. Em ambas as partes, os entrevistados deveriam dar uma nota para as sentenças apresentadas. A escala utilizada na avaliação das sentenças variava de 1 a 5 em todas as duas partes, porém, nas sentenças que avaliavam o nível de serviço ofertado, o 1 correspondia a "Pouco Importante" e 5 à "Muito Importante". Já nas questões referentes ao nível de serviço ofertado, o 1 correspondia a "Discordo Muito" e o 5 a "Concordo Muito".

O teste qui-quadrado, foi utilizado para avaliar a distribuição da avaliação dos clientes, quanto ao serviço ofertado e esperado, analisando se as amostras se diferem quanto à proporção desses acontecimentos. Ou seja, através dessa análise foi possível perceber se existe para os entrevistados uma diferença entre o nível de serviço esperado e o ofertado pelas farmácias.

Tabela 5 - Teste qui-quadrado do fator tangibilidade

\begin{tabular}{|c|c|c|c|c|}
\hline$\chi^{\mathbf{2}}$ calculado & $\chi^{\mathbf{2}}$ tabelado & $\begin{array}{c}\text { Graus de } \\
\text { liberdade }\end{array}$ & $\begin{array}{c}\text { Valor da } \\
\text { probabilidade }\end{array}$ & $\begin{array}{c}\text { Nível de } \\
\text { significância }\end{array}$ \\
\hline $\mathbf{1 7 , 2 0 4}$ & $\mathbf{9 , 4 8 8}$ & $\mathbf{4}$ & $\mathbf{0 , 0 0 2}$ & $\mathbf{0 , 0 5}$ \\
\hline
\end{tabular}

Como o $\chi^{2}$ calculado foi maior que o $\chi^{2}$ tabelado, rejeita-se a hipótese nula, ou seja, as freqüências observadas são diferentes entre si. Podemos dizer então que, nos aspectos relacionados à Tangibilidade, há na percepção dos entrevistados uma diferença entre o nível de serviço esperado e o ofertado. Os aspectos analisados nesta dimensão foram: aspecto físico da loja como as instalações e equipamentos, a proximidade do estabelecimento, a aparência dos funcionários, o nome (marca) da farmácia. Podemos afirmar, então, que, em relação ao conjunto destes fatores, o nível de serviço esperado é maior que o nível de serviço ofertado.

Tabela 6 - Teste qui-quadrado do fator confiabilidade

\begin{tabular}{|c|c|c|c|c|}
\hline$\chi^{2}$ calculado & $\chi^{2}$ tabelado & $\begin{array}{c}\text { Graus de } \\
\text { liberdade }\end{array}$ & $\begin{array}{c}\text { Valor da } \\
\text { probabilidade }\end{array}$ & $\begin{array}{c}\text { Nível de } \\
\text { significância }\end{array}$ \\
\hline 27,436 & $\mathbf{9 , 4 8 8}$ & 4 & $1,62218 E-05$ & $\mathbf{0 , 0 5}$ \\
\hline
\end{tabular}

Fonte: Elaborado pelos autores (2011).

REAd | Porto Alegre - Edição 77 - N 1 - janeiro/abril 2014 - p. 64-89 
Relacionamento com clientes do setor farmacêutico em Vitória-ES: uma análise dos impactos do nível de serviço esperado e ofertado na fidelização dos clientes

No fator confiabilidade, também houve rejeição da hipótese nula, o que demonstra que para aspectos analisados dentro desses fatores, as percepções dos serviços ofertados e esperados também não foram proporcionais. Podemos dizer que na dimensão Confiabilidade - serviços prestados de maneira certa, cumprimento de prazos, oferta de produtos e serviços de qualidade - o nível esperado é maior que o nível de serviço ofertado pelas empresas.

Tabela 7 - Teste qui-quadrado do fator Responsividade

\begin{tabular}{|c|c|c|c|c|}
\hline$\chi^{2}$ calculado & $\chi^{2}$ tabelado & $\begin{array}{c}\text { Graus de } \\
\text { liberdade }\end{array}$ & $\begin{array}{c}\text { Valor da } \\
\text { probabilidade }\end{array}$ & $\begin{array}{c}\text { Nível de } \\
\text { significância }\end{array}$ \\
\hline $\mathbf{2 3 , 9 4 1}$ & $\mathbf{9 , 4 8 8}$ & 4 & $\mathbf{8 , 2 0 9 0 1 E - 0 5}$ & $\mathbf{0 , 0 5}$ \\
\hline
\end{tabular}

Fonte: Elaborado pelos autores (2011).

Quando se realiza uma análise dos aspectos relativos à Responsividade, verificamos a mesma relação que nas dimensões anteriormente analisadas. Também nos serviços dessa dimensão, as farmácias não oferecem um nível de serviço adequado às expectativas esperadas pelos clientes. A dimensão Responsividade, avaliou se os funcionários das farmácias prestam os serviços prontamente; se estão sempre dispostos e prontos a atender e a ajudar os clientes; e se a farmácia oferece serviços de entrega a domicílio e formas de pagamento facilitada.

Tabela 8 - Teste qui-quadrado do fator Segurança

\begin{tabular}{|c|c|c|c|c|}
\hline$\chi^{2}$ calculado & $\chi^{2}$ tabelado & $\begin{array}{c}\text { Graus de } \\
\text { liberdade }\end{array}$ & $\begin{array}{c}\text { Valor da } \\
\text { probabilidade }\end{array}$ & $\begin{array}{c}\text { Nível de } \\
\text { significância }\end{array}$ \\
\hline $\mathbf{6 , 2 0 7}$ & $\mathbf{9 , 4 8 8}$ & $\mathbf{4}$ & $\mathbf{0 , 1 8 4}$ & $\mathbf{0 , 0 5}$ \\
\hline
\end{tabular}

Fonte: Elaborado pelos autores (2011).

Na dimensão Segurança, observou-se que o $\chi^{2}$ calculado é menor que o $\chi^{2}$ tabelado, o que indica que a Hipótese nula deve ser aceita, ou seja, as frequiências observadas não são diferentes das esperadas e é mantida a proporcionalidade entre as frequiências. Não houve alterações significativas nos aspectos relacionados à Segurança, portanto, a percepção dos clientes nesta dimensão não varia do nível de serviço esperado para o ofertado. Os aspectos analisados nesta dimensão foram: confiança dos clientes em relação à farmácia; gentileza, cordialidade, agilidade e conhecimento dos funcionários.

Esse resultado indica que nessa dimensão as farmácias estão conseguindo oferecer um nível de serviço adequado ao nível esperado pelos clientes. 
Mikaelli Orlande Gabriel, Anderson Soncini Pelissari \& Marcos Paulo Valadares de Oliveira

Tabela 9 - Teste qui-quadrado do fator Empatia

\begin{tabular}{|c|c|c|c|c|}
\hline$\chi^{2}$ calculado & $\chi^{2}$ tabelado & $\begin{array}{c}\text { Graus de } \\
\text { liberdade }\end{array}$ & $\begin{array}{c}\text { Valor da } \\
\text { probabilidade }\end{array}$ & $\begin{array}{c}\text { Nível de } \\
\text { significância }\end{array}$ \\
\hline 27,252 & 9,488 & 4 & $1,76761 E-05$ & 0,05 \\
\hline
\end{tabular}

Fonte: Elaborado pelos autores (2011).

Por fim, foi analisado o fator Empatia e verificou-se nesse fator também que, as frequiências observadas são diferentes entre si e que mais uma vez o nível de serviço esperado é maior que o nível de serviço ofertado pelas farmácias. Nesta dimensão, foram avaliados os seguintes aspectos: se os funcionários compreendem as necessidades específicas dos clientes; se a farmácia oferece um atendimento individualizado e por fim, se a farmácia oferece serviços como atendimento $24 \mathrm{~h}$ e cartão de fidelidade. Ao avaliarmos os scores de notas obtidas nos níveis de serviço esperado e no nível de serviço ofertado, para as quatro dimensões da Escala SERVQUAL que não apresentaram comportamento homogêneo para os dois níveis de serviço estudados, observamos que o nível de serviço ofertado recebeu sempre as menores notas, indicando que o nível de serviço ofertado pelas farmácias nessas dimensões é inferior ao nível de serviço esperado pelos entrevistados.

\subsection{Análise das variáveis moderadoras}

Para as variáveis moderadoras - Região, Gênero, Idade, Estado Civil, Grau de Instrução e Renda - realizou-se o teste de Análise de Variância, tomando no intuito de verificar se os diferentes grupos que compõem essas variáveis exercem influência no comportamento dos entrevistados. A ANOVA foi realizada para as seguintes questões: Freqüência de Compra; Tempo de clientela; e Nível de satisfação. Não foram encontradas diferenças significativas, entre os grupos citados anteriormente, para nenhuma dessas questões.

\section{CONSIDERAÇÕES FINAIS}

A presente pesquisa teve por objetivo central, avaliar as possíveis relações entre o nível de serviço esperado, o nível de serviço ofertado e a fidelização do cliente no varejo farmacêutico na cidade de Vitória, Espírito Santo. Através do teste das hipóteses levantadas, foi possível alcançar esse fim. Das seis hipóteses levantadas, apenas as hipóteses 5 e 6 foram aceitas, ou seja, as únicas relações verificadas foram: a de que quanto maior a avaliação dos clientes para o nível de serviço ofertado maior também o nível de satisfação dos clientes; e a de que quanto menor a diferença entre o nível de serviço esperado e o nível de serviço ofertado, maior a satisfação dos clientes.

REAd | Porto Alegre - Edição 77 - N 1 - janeiro/abril 2014 - p. 64-89 
Relacionamento com clientes do setor farmacêutico em Vitória-ES: uma análise dos impactos do nível de serviço esperado e ofertado na fidelização dos clientes

Não foram encontradas relações consideráveis entre o nível de serviço ofertado pelas empresas e a frequiência de compra dos clientes ou ainda com relação ao tempo de clientela. Assim, pode-se dizer que o nível de serviço ofertado afeta a satisfação dos clientes das farmácias da cidade de Vitória, mas não é responsável diretamente pela fidelização deles, podendo estar entre os fatores que influenciam a fidelização, mas não sendo fator determinante para tal.

Ao realizarmos o teste qui-quadrado para as cinco dimensões da Escala SERVQUAL observou-se que em apenas uma das dimensões os níveis de serviço ofertado está ajustando ao nível de serviço esperado pelos clientes. Trata-se da dimensão Segurança, o que indica que nos aspectos confiança dos clientes em relação à farmácia, bem como gentileza, cordialidade, agilidade e conhecimento dos funcionários as farmácias estão conseguindo oferecer um nível de serviço adequado ao nível esperado pelos clientes.

Para aumentar a satisfação de seus clientes, as farmácias da cidade de Vitória devem melhorar o nível do serviço ofertado nos fatores que abrangem as dimensões Tangibilidade, Confiabilidade, Responsividade e Empatia.

Para oferecer um nível de serviço mais adequado ao esperado pelo cliente as empresas devem investir, no que se refere à dimensão Tangibilidade, em instalações mais organizadas, limpas e com design agradável; estacionamento; apresentação dos funcionários; e, a longo prazo, trabalhar para o reconhecimento de sua marca.

Para um melhor desempenho na dimensão Confiabilidade, as empresas devem cumprir os prazos prometidos, bem como investir esforços em treinar seus funcionários no sentido de prestar serviços com exatidão. Além disso, devem ainda estar atentas as demandas dos consumidores para ofertar sempre o produto procurado.

$\mathrm{Na}$ dimensão Responsividade os investimentos se assemelham aos da confiabilidade, os funcionários devem estar treinados para atender prontamente aos clientes. Um ponto de atenção aqui é a qualidade dos atendimentos feitos pela empresa por telefone, correio eletrônico ou site da internet. Além disso, a análise dessa dimensão mostrou discrepância no nível de serviço facilitado ofertado pelas farmácias e o esperado pelos clientes nos aspectos: entrega a domicilio e formas de pagamento facilitado ofertado pelas farmácias. Destaca-se que algumas vezes estes serviços podem ser inexistentes.

Por fim, na analise da dimensão Empatia, pode-se concluir que as farmácias devem investir em aspectos como atendimento $24 \mathrm{~h}$ e oferta de vantagens com o cartão fidelidade. Mais uma 
Mikaelli Orlande Gabriel, Anderson Soncini Pelissari \& Marcos Paulo Valadares de Oliveira

vez deve-se treinar os funcionários, dessa vez para atender de forma individualizada e para mostrar que compreendem as necessidades específicas dos clientes.

Como restrição, destaca-se o tamanho do questionário utilizado, por apresentar-se muito extenso para esse tipo de pesquisa. Este fato não foi identificado no pré-teste, mas alguns entrevistados demonstraram um pouco de impaciência com o questionário, o que pode ter alterado seu comprometimento com a exatidão das respostas.

Diante do que foi apresentado neste trabalho, sugere-se para pesquisas futuras um estudo mais detalhado a respeitos dos fatores geradores de satisfação nos clientes do setor farmacêutico. Sugere-se, também, uma pesquisa mais aprofundada para identificar outros fatores que possam ser responsáveis pela fidelização nesse setor.

\section{REFERÊNCIAS}

ANDERSON, E. W.; FORNELL, C.; LEHMANN, D.R. Perceived quality, customer satisfaction,market share, and profitability. Working Paper, NQRC (National Quality

Research Center): The University of Michigan, 1992.

BARNES, J. G. Segredos da gestão pelo relacionamento com os clientes-CRM: é tudo uma questão de como você faz com que eles se sintam. Rio de Janeiro: Qualitymark, 2002.

BERNI, D. de Á. Técnicas de Pesquisa em Economia. São Paulo: Saraiva, 2002.

BERRY, L. L.; PARASURAMAN, A. Serviços de marketing: competindo através da qualidade. São Paulo: Maltese: Norma, 1992.

BOONE, L. E.; KURTZ, D. L. Marketing contemporâneo. São Paulo, SP: Cengage Learning, 2009.

BREI, V. A.; ROSSI, C. A. V. Confiança, valor percebido e lealdade em trocas relacionais de serviços: Um estudo com usuários de internet banking no Brasil. Revista de Administração Contemporânea, RAC. V.9, n. 2, abril/junho 2005.

CERVO, A. L.; BERVIAN, P. A.; SILVA, R. da. Metodologia científica. 6. ed. São Paulo: Prentice Hall, 2007.

COMFAR (COMISSÃO DE FARMÁCIA DO CONSELHO FEDERAL DE FARMÁCIA). Planejamento Estratégico Empresarial: Marketing em Farmácias Drogarias. Ano I, no 8. REAd | Porto Alegre - Edição 77 - N 1 - janeiro/abril 2014 - p. 64-89 
Relacionamento com clientes do setor farmacêutico em Vitória-ES: uma análise dos impactos do nível de serviço esperado e ofertado na fidelização dos clientes

Marços/abril, 2008. Disponível em:

$\langle$ http://www.cff.org.br/sistemas/geral/revista/pdf/4/encarte_pgs_centrais.pdf $>$. Acesso em: 10 set. 2010

CORRÊA, G. B. F. Comportamento do consumidor e a qualidade no atendimento do varejo farmacêutico. In: VII SEMEAD, jul. 2004, São Paulo. Disponível em:

$<$ http://www.ead.fea.usp.br/Semead/7semead/paginas/artigos\%20recebidos/marketing/MKT1 9_-_Comportamento_do_consumidor_e_a_qualid.pdf>. Acesso em 15 ago. 2010.

CORRÊA, H. L.; CAON, M. Gestão de serviços: lucratividade por meio de operações e de satisfação dos clientes. São Paulo: Atlas, 2008.

GORDON, I. Marketing de relacionamento. Estratégias, técnicas e tecnologias para conquistar clientes e mantê-los para sempre. São Paulo: Futura, 1998.

GOUVEA, M. A.; BIAZZI, M. R. O comportamento do consumidor do setor farmacêutico diante da demanda não atendida - implicações para a cadeia de suprimentos. RAM. Revista de Administração Mackenzie, v. 08, p. 12-30, 2007.

CRESCITELLI, Edson; GUIMARÃES, C. T.; MILANI, G. F. Marketing de relacionamento aplicado ao varejo: uma proposta de programa de fidelização. Revista de Administração da UNIMEP, v. 4, n. 1, Janeiro / Abril, p. 1 a 21, 2006.

HSM ONLINE. A era da conveniência. Disponível em:

<http://www.hsm.com.br/editorias/era-da-conveniencia >. Acesso em: 19 out. 2010.

IBGE. População do Município de Vitória-ES, 2010. Disponível em:

<http://www.ibge.com.br>. Acesso em 25 mar. 2012.

KANNITZ, S. Farmacêutico, 2010. Disponível em: $<$ http://www.americamarketing.com.br/america-radar/ambientenacional/industrial/farmaceutico/ > Acesso em: 23 Ago. 2010.

KAPLAN, R. S.; NORTON, D. P. A estratégia em ação: balanced scorecard. 24. ed. Rio de Janeiro: Elsevier, 1997.

KOTLER, P. Princípios de marketing. 12 ed. São Paulo: Pearson Prentice Hall, 2007.

KOTLER, P.; HAYES, T.; BLOOM, P. N. Marketing de Serviços Profissionais: Estratégias Inovadoras para Impulsionar sua Atividade, sua Imagem e seus Lucros. 2. ed. São Paulo: Manole, 2002. 
Mikaelli Orlande Gabriel, Anderson Soncini Pelissari \& Marcos Paulo Valadares de Oliveira

LAKATOS, E. M.; MARCONI, M. de A. Metodologia científica: ciência e conhecimento científico, métodos científicos, teoria, hipóteses e variáveis, metodologia jurídica. 4. ed. rev. e ampl. - São Paulo: Atlas, 2004.

LINS, Samuel Lincoln Bezerra; NUNES, A. V. L.; LIMA, W. V. Qualidade de serviços: um estudo de caso no setor de carros seminovos. Revista de Administração da UNIMEP, v. 7, p. 1-24, 2009.

LOPES, H. E. G. et al. Comparação entre os modelos norte-americano (ACSI) e europeu (ECSI) de satisfação do cliente: um estudo no setor de serviços. RAM. Revista de Administração Mackenzie, V. 10, jan/fev 2009, 161-187.

LOVELOCK, C.; WIRTZ, J. Marketing de serviços: pessoas, tecnologia e resultados. São Paulo: Pearson, 2006

LOVELOCK, C.; WRIGHT, L.. Serviços: marketing e gestão. São Paulo: Saraiva, 2001.

LUIZ, M. C.; BRAGA, A. V. O que você precisa saber sobre: Farmácia. Porto Alegre: SEBRAE/RS, 2006.

MELLO, C. M.; VIEIRA, F. G. D. Marketing de relacionamento: um estudo empírico em micro e pequenas empresas do comércio varejista de Campo Mourão/PR. Perspectivas Contemporâneas, v. 3, p. 109-130, 2008.

MOTA, M. de O.; FREITAS, A. A. F. Análise dos Benefícios Relacionais Observados por Usuários de Serviços. RAM. Revista de Administração Mackenzie, V. 9, set/out 2008, 126147.

OLBRZYMEK, J. R.; OLBRZYMEK, M. R.; BRETZKE, R. O. Marketing de relacionamento: grandes projetos não envolvem somente tecnologia. Revista Agathos, ano I, n. $1,2005$.

PARASURAMAN, A., ZEITHAML, V.A., BERRY, L.L. A conceptual model of service quality and its implications for future research. Journal of Marketing, USA, v. 49, n. 4, p. 41-50, fall 1985.

Servqual: a multiple-item scale for measuring consumer perception of service quality. Journal of Retailing, vol. 64, n.1, Spring, 1988.

PARENTE, J. Varejo no Brasil: Gestão e Estratégia. 1 ed. São Paulo: Atlas, 2009. 
Relacionamento com clientes do setor farmacêutico em Vitória-ES: uma análise dos impactos do nível de serviço esperado e ofertado na fidelização dos clientes

PELISSARI, Anderson Soncini; OLIVEIRA, A. R.; GONZALEZ, Inayara Valéria Defreitas Pedroso; FABRINI, M. F.; SILVEIRA, R. C. da. Determinantes da satisfação dos clientes: Estudo de caso em uma loja de departamentos. Revista de Administração da UNIMEP, v. 9, p. 32-48, 2011.

PEPPERS, D.; ROGERS, M. Marketing um a um: marketing individualizado na era do cliente. Rio de Janeiro: Campus, 1994.

CRM Series Call Center 1 to 1: um guia executivo para transformar Call centers em Centros de Interação com Clientes. 2ed. São Paulo: Makron Books, 2001.

PEREIRA, P. F. P.; BASTOS, F. C. Um estudo sobre a fidelização de clientes a partir de estratégias de marketing de relacionamento no segmento de farmácias e drogarias. In: In: VI Simpósio de Excelência em Gestão e Tecnologia - SEGeT, 2009, Resende. Anais do VI SEGeT. Resende: AEDB, 2009. Disponível em:

<http://www.aedb.br/seget/artigos09/229_Artigo_Seget_utima_versao.pdf > Acesso em 15 ago. 2010 .

PORTER, M. E. Estratégia competitiva: técnicas para análise de indústrias e da concorrência. 2. ed. - Rio de Janeiro: Elsevier, 2004

RICHARDSON, R. J. Pesquisa social: métodos e técnicas. 3. ed. rev. e ampl. - São Paulo: Atlas, 1999.

ROCHA, A. da.; CHRISTENSEN, C. Marketing: teoria e pratica no Brasil. 2. ed. - São Paulo: Atlas, 1999.

RODRIGUES, A. C. M. Uma escala de mensuração da zona de tolerância de consumidores de serviços. RAC. Revista de Administração Contemporânea, v. 5. n. 2, p.113-134, maio/ago, 2001.

ROSSI, P. E.; BRAGA, S. P. A Satisfação dos clientes em relação aos serviços prestados por um organismo de Inspeção veicular. Revista Administração OnLine V.5, n.3, jul/ago/set. 2004.

RUST, R. T.; ZEITHAML, V;LEMON, K. N. O valor do cliente: o modelo que está reformulando a estratégia corporativa: customer equity. Porto Alegre: Bookman, 2001.

SAAB, W.; RIBEIRO, R. Um panorama do varejo de farmácias e de drogarias no Brasil. Informe Setorial. Rio de Janeiro: BNDES, mar 2001. Disponível em: <http://www.bndes.gov.br/SiteBNDES/export/sites/default/bndes_pt/Galerias/Arquivos/conhe cimento/setorial/get4is25.pdf>. Acesso em 11 de ago. 2010. 
Mikaelli Orlande Gabriel, Anderson Soncini Pelissari \& Marcos Paulo Valadares de Oliveira

SALIBY, E. P. O Marketing de Relacionamento: o novo marketing da nova era competitiva. Revista Administração de Empresas - RAE LIGHT, São Paulo, v.37, n. 03, JulhoSetembro 1997. Disponível em: < http://www16.fgv.br/rae/artigos/278.pdf >. Acesso em: 27 ago. 2010

SALOMON, H. J. A terceira mídia: como os brindes potencializam as marcas, melhoram os relacionamentos e aumentam as vendas. São Paulo: Futura, 2008.

SANTOS, E. V. dos. Globalização e Desenvolvimento Regional. In: Negócios e Talentos, 2008 v. 5, porto alegre. Disponível em:

$<$ http://seer.uniritter.edu.br/index.php/negocios/article/viewFile/119/42> Acesso em 3 set. 2010

SEBRAE. Idéias de negócios: Drogarias. Disponível em: $<$ http://www.sebrae.com.br/setor/comercio-varejista/segmentosapoiados/farmacias/integra_ideia?rs=Drogaria\&id=E34D1B2FBD71A959832575AC006D2E DD\&campo=impNeg> Acesso em 16 ago. 2010.

Análise de negócios: Drogarias. Espírito Santo: SEBRAE/ES. Mar 2000.

TOLEDO, G. L.; IKEDA, Ana Akemi; OLIVEIRA, B. A. C. Fidelização e valor: uma interdependência inequívoca. In: VII SEMEAD - Seminários em Administração, 2004, São Paulo. VII Semead - Seminários em Administração, 2004.

VAVRA, T. G. Marketing de relacionamento: aftermarketing. São Paulo: Atlas, 1993.

YAMASHITA, S. S.; GOUVEA, M. A. Marketing de Relacionamento: Importância e Implicações no Mercado Consumidor. RAM. Revista de Administração Mackenzie, v. 8, p. 103-124, 2007.

ZEITHAML, V. A.; PARASURAMAN, A.; BERRY, L. L. Problems and strategies in service marketing. Journal of Marketing, n.52, spring, p.33-46, 1985.

ZEITHAML, V. A.; BITNER, M. J. Marketing de serviços. Porto Alegre: Bookman, 2003. 